\title{
THE IMPACT OF USING SOCIAL MEDIA PLATFORMS IN BUSINESS PROMOTION
}

\author{
OANa PRICOPOAIA ${ }^{a^{*}, \text { Irina SUSANU }}{ }^{b}$ \\ ${ }^{a}$ Transilvania University of Brașov, Romania \\ ${ }^{b}$ Dunarea de Jos University of Galați, Romania
}

\begin{abstract}
Social media is not just about socializing or interpersonal communication, it is about the transmission of information in order to influence public opinion and to shape a particular consumption behavior. Social media can be considered media of the future because companies promote Internet activity to attract the attention of the target audience. Social media platforms are an effective, interactive, and fast means of communication for both individuals and the legal persons. For companies present in the online environment, the connection with customers is direct, the campaign promotion can be monitored through special digital tools and the results of the campaign are easy to be quantified. In online promotion it is necessary to know the target audience because the message must be customized according to the requirements, constantly updated because the online customer is always stirred towards novelty and be attractiveness, original and relevant to the promoted object. Content transmitted targets a well-defined audience and influences through objective and valuable information. Social media is a tool for social interaction and a form of two-way communication based on online services. Thus, social media marketing must become a priority for all companies that want a successful business, because they can increase the company's notoriety, customer loyalty, improve relationship with the customers and gaining a favorable image in the market.
\end{abstract}

KEYWORDS: advertising, digital marketing, Internet, media, social media platforms.

\section{DOI: 10.24818/IMC/2021/05.10}

\section{INTRODUCTION}

Social media allows people to connect to the online environment and develop relations of friendship or business. Social media users can share their experiences online following the use of a product, may ask for opinions about a particular service or interact directly with content. Thus, consumers feel more involved in creating and sharing messages distributed by a company in the online environment. Social media marketing platforms used correctly in online promotion bring a multitude of benefits to companies among which the most significant are: increasing customer satisfaction and improving the image of the market. Companies that choose to integrate social media marketing into their strategy benefit from a form of internet marketing based on web applications and media channels for generating direct interactions with the public.

The Internet was the factor that most influenced the cultural, economic, and social changes observed at the beginning of the 21 st century. Now, the consumer is the focal point of business and the target of Internet strategies (García et al., 2019). Thus, before launching a promotion campaign, the company must check which of the online platforms is the most suitable for carrying out the advertising of its activity, which are the platforms on which the competitors are successful and which advertising elements work. In order to successfully apply a strategy, the company must know

\footnotetext{
*Corresponding author. E-mail address: oana.pricopoaia@unitbv.ro
} 
the current context, the trends in online promotion, the news on the business market and the digital promotion tools. Video content gives the audience a sense of closeness to the company, is interactive and maintains attention for longer than written advertising. Buying behavior can be more easily influenced in the online space, collaborative relationships develop much faster, members of social networks are gathered in virtual communities, share opinions and influence the purchasing activity.

\section{USING FACEBOOK TO PROMOTE THE COMPANY}

The companies present in the online environment consider the potential audience on Facebook, and therefore this they create unique campaigns, which attract attention and want to get more and more supporters. Marketing and advertising experts believe that evening posts have a higher success rate than those distributed at lunch. The explanation would be that many people relax in the evening before bedtime using their phone or tablet connected to the Internet. Also, the content on social media has more success materialized by the number of views and reactions from users during the week, especially on Tuesday, Wednesday and Thursday because on weekends many people pay attention to other aspects related to the holiday, free time spent with family or other favorite activities. Facebook was initially used only for communication, but companies realized its real value and integrated it into the marketing strategy (Varma et al., 2020). Under these conditions, marketers must be as active and informed as possible about the news in the online environment. For the success of the campaign carried out on social media, the content posted counts, but also the strategy adopted, so that the time a person spends on Facebook draws their attention to the targeted aspect. The promotion on Facebook emphasizes creativity, the idea of friendship, support and novelty because they will later help generate leads.

Social media is an umbrella term for web-based software and services that allow users to come together online and exchange information, communicate, and participate in any form of social interaction (Ryan et al., 2009). Through the Facebook page, the company's image is improved, existing customers can be more loyal and new categories of customers are attracted more quickly. Even if at the moment Instagram enjoys an essential growth among young people, Facebook is still the most used social network in Romania. Over 10 million users have a Facebook account, which means that more than half of the population in our country is present on this platform. Also, globally Facebook registered in 2020 an increase of 9\% compared to 2019 among users.

Internet reviews can cause changes in consumer attitudes and buying behaviors, affecting the performance of companies. Currently, Facebook currently records the activity of 2.45 billion users, who are active monthly. The people who work most often on Facebook are between 25 and 34 years old, representing $30 \%$ of the total number of Internet users. This category of users is considered the category of "key consumers" of the Facebook platform, and from the point of view of companies are seen as the target audience for exposure in the online environment. Facebook marketing has seen a significant increase due to promotion through video content, since 2018 Facebook video has become the focal point of content, also in this category live shows have a higher usage rate, compared to regular posts.

This success can be justified by the possibility offered to brands to interact directly with the target audience, this real-time communication is also reinforced by the notifications sent by Facebook to the followers of a page when it enters the show.

Core Facebook Vitals reported in the Q3 2020 IR Statement (updated by Facebook on 29.10.2020):

- over 2.74 billion monthly active users worldwide;

- about 1.82 billion people connect to Facebook every day and are considered active users every day;

- Facebook is in the top 3 most visited websites, on the 1st place being Google, on the 2nd place YouTube; 
- about $75 \%$ of people with above average incomes use Facebook daily, which proves that it can be a very good form of advertising for companies that want to increase their number of customers;

- COVID-19 crisis has significantly influenced this time of use, spending too much time at home and not socializing face to face, people are tempted to spend more time on social networks reducing this lack of communication and finally to spend more time on Facebook, use exceeding 38 minutes a day.

Between October 2019 and October 2020, Facebook users in Romania distributed by gender and age categories are:

Table 1. Number of Facebook users by gender

\begin{tabular}{|c|c|c|}
\hline \multicolumn{3}{|c|}{ reference period - October 2019 } \\
\hline Total number of users & female users & male users \\
\hline 105300000 & $50,7 \%$ & $49,3 \%$ \\
\hline \multicolumn{3}{|c|}{ reference period - October 2020 } \\
\hline Total number of users & female users & male users \\
\hline 11160000 & $50,5 \%$ & $49,5 \%$ \\
\hline
\end{tabular}

Source: adapted from https://napoleoncat.com/stats/facebook-users-in-romania/2019/10/

Table 2. Number of Facebook users by age categories

\begin{tabular}{|c|c|c|c|c|c|c|c|}
\hline $\begin{array}{c}\text { Age category of } \\
\text { Facebook users }\end{array}$ & $\begin{array}{c}13-17 \\
\text { years }\end{array}$ & $\begin{array}{c}18-24 \\
\text { years }\end{array}$ & $\begin{array}{c}25-34 \\
\text { years }\end{array}$ & $\begin{array}{c}35-44 \\
\text { years }\end{array}$ & $\begin{array}{c}45-54 \\
\text { years }\end{array}$ & $\begin{array}{c}55-64 \\
\text { years }\end{array}$ & $>65$ years \\
\hline October 2019 & $4,5 \%$ & $18,6 \%$ & $25,6 \%$ & $20,9 \%$ & $16,5 \%$ & $9,1 \%$ & $4,7 \%$ \\
\hline Age category of & $13-17$ & $18-24$ & $25-34$ & $35-44$ & $45-54$ & $55-64$ & $>65 y e a r s$ \\
Facebook users & years & years & years & $\begin{array}{c}\text { years } \\
\text { years }\end{array}$ & years & \\
\hline October 2020 & $4,4 \%$ & $17,9 \%$ & $24,2 \%$ & $20,6 \%$ & $17,4 \%$ & $9,6 \%$ & $5,9 \%$ \\
\hline
\end{tabular}

Source: adapted from https://napoleoncat.com/stats/facebook-users-in-romania/2019/10

The use of social media in the digital strategy brings significant brand awareness opportunities and direct conversion opportunities. Facebook, for example, provides paid campaigns, company pages, and even information for performance analysis (Kingsnorth, 2016). So, the Facebook page brings many advantages including: access to a new, extended and diverse audience, strengthening the brand, the image is much stronger, has an impact on the public, the relationship with potential customers is much easier to connect, and with existing ones it gets stronger, informing customers is much faster and easier and it is closer to the audience and the built community.

\section{ADVERTISING ON INSTAGRAM}

Instagram was launched in October 2010, and currently in Romania it is widely used among young people because it attracted attention by promoting trends (selfies, inspirational pictures, pictures with quotes, holidays, etc.). Using Instagram is a creative way to keep in touch with your audience or gain new audiences. The pictures inside the company, for example: the employee of the year, the employees while working smiling, the children at the company at the employees' Christmas party can favor the strengthening of the company-public relationship. The company active on Instagram gets multiple benefits without too much effort: visibility increases the number of followers and the relationship with the audience is improved.

Instagram is on the 2nd place in Romania in the top of the most used social media platforms, having 4 million users at the moment. Since 2016, there has been an increase in the number of users. The 
digital consumer is the person who grew up in the Internet world, a more conscious consumer and less prone to influence (Tkaczyk, 2016). The interaction with the audience can be maintained through the comments posted, questions or remarks of the audience to which the brand will respond. On Instagram, the Influencer Marketing trend is constantly growing, content creators help the brand to be better known and appreciated by the target audience. Brands resort to influences to promote the company, the company's results being immediate and known through a number of followers. The story on Instagram is valid only for a short time and after it disappears, it attracts the attention of followers because they are interactive and impactful, supporting the explanation that long-term attention is quickly lost.

Instagram has also tested in several countries a version of the application in which the number of likes is no longer visible, the explanation for this change is that the number of likes has become for some just a tool to measure the level of social value of a person, and this measure of counting likes does not support mental health. However, we returned to the initial idea of displaying the number of appreciations for marketing reasons. The promotion on Instagram is done quickly and very easily, through suggestive, attractive and colorful images.

Between October 2019 and October 2020, Instagram users in Romania distributed by age and gender categories are:

Table 3. Number of Instagram users by age

\begin{tabular}{|c|c|c|c|c|c|c|c|}
\hline $\begin{array}{c}\text { Age category of } \\
\text { Instagram users }\end{array}$ & $\begin{array}{c}13-17 \\
\text { years }\end{array}$ & $\begin{array}{c}18-24 \\
\text { years }\end{array}$ & $\begin{array}{c}25-34 \\
\text { years }\end{array}$ & $\begin{array}{c}35-44 \\
\text { years }\end{array}$ & $\begin{array}{c}45-54 \\
\text { years }\end{array}$ & $\begin{array}{c}55-64 \\
\text { years }\end{array}$ & $\begin{array}{c}>65 \\
\text { years }\end{array}$ \\
\hline October 2019 & $9,1 \%$ & $35,2 \%$ & $29,7 \%$ & $15,1 \%$ & $7,4 \%$ & $2,2 \%$ & $1,3 \%$ \\
\hline Age category of & $13-17$ & $18-24$ & $25-34$ & $35-44$ & $45-54$ & $55-64$ & $>65$ \\
Instagram users & years & years & years & years & years & years & years \\
\hline October 2019 & $8,1 \%$ & $32,7 \%$ & $29,1 \%$ & $16,2 \%$ & $9 \%$ & $3 \%$ & $1,9 \%$ \\
\hline
\end{tabular}

Source: adapted from https://napoleoncat.com/stats/instagram-users-in-romania/2019/10

Table 4. Number of Instagram users by gender

\begin{tabular}{|c|c|c|}
\hline \multicolumn{3}{|c|}{ reference period - October 2019 } \\
\hline $\begin{array}{c}\text { Total number of Instagram } \\
\text { users }\end{array}$ & female users & male users \\
\hline 3635000 & $53,2 \%$ & $46,8 \%$ \\
\hline \multicolumn{2}{|c|}{ reference period - October 2020 } \\
\hline $\begin{array}{c}\text { Total number of Instagram } \\
\text { users }\end{array}$ & female users & male users \\
\hline 4563000 & $53,2 \%$ & $46,8 \%$ \\
\hline
\end{tabular}

Source: adapted from https://napoleoncat.com/stats/instagram-users-in-romania/2020/10/

It can be seen from the above data that women more often use virtual platforms such as Instagram, Pinterest or Snapchat, and men choose more active platforms such as Facebook and TikTok. Thus, targeting the audience is important, and understanding, collecting and interpreting demographic data is necessary. Ephemeral content is becoming more popular because there is an increase in the number of minutes spent on Instagram. If the company chooses to post videos, they will be uploaded to Instagram Story, the content will be visible for 24 hours. Product tags can be added to the posted images, and the audience can more easily buy the products by seeing the information in real time, so sales increase by promoting on Instagram through discounts or prizes offered. Influencers are ordinary people, who are gaining popularity on social networks by posting visually appealing content (photos and videos), and by interacting with other users create a sense of authenticity and friendship (Argyrisa et al., 2020). 
Instagram Stories uploads videos (tutorials) through which people are taught to use certain products. The company considers: the time interval in which it posts the advertisement, the distributed content and the target audience so that the advertising is not perceived as disturbing. Professionally made pictures emphasize the aesthetic side, quality, and visual content positively influencing the audience, and the target audience finds faster the products to which the company refers. The company's Instagram account is successful if it attracts fans, celebrities or involves brand ambassadors because it reaches the target audience faster. Quality content attracts several categories of audience, each person who joins the brand has a different personality, a creative imagination and a different vision.

\section{MARKETING ON YOUTUBE}

YouTube was launched in 2005, and is currently the largest video content channel, being a video sharing platform made up of billions of videos uploaded by users. Users can have an account or not, those who have an account can add videos, like, dislike, comment, and upload for free. The Internet, social media, mobile applications and other digital communication technologies have become part of everyday life for billions of people around the world. According to recent January 2020 statistics, 4.54 billion people are active Internet users, representing 59\% of the global population (Dwivedi et al., 2020).

Marketing means more than advertising (Scott, 2010). Thus, the company that wants to promote itself on YouTube must consider several aspects regarding the type of video promoted, the way it is distributed to the public, to add a suggestive title and an attractive description. Sales increase through promotion on YouTube because you can demonstrate the use of products, you can create communities around the desired product, you can find out the opinion of users directly from the comments, adding a link to the company's website users will access the site faster the company.

Presenting a product through videos has a greater impact on the target audience because the video format attracts attention faster and more strongly compared to a picture or text, thus helping consumers more in choosing the desired products. A community can be created on YouTube through which the interaction between the brand and users is direct, the audience being encouraged to follow the YouTube channel and subscribe for future news.

Social tools are technologies which allow people to contribute to content creation and influence the web environment as a whole. Video sharing sites such as YouTube offer the opportunity to experiment and promote services, resources, or locations (Cheng et al., 2020). With the help of the YouTube platform, informative videos are made through which the public better understands the aspects that are presented to them. Paid advertising can also be used for added value.

YouTube is the largest search engine for video sharing content with heavy traffic, which must be considered by companies. YouTube provides functionality directly to the audience, for example: a live event can be streamed online or a virtual meeting with the consumer can be arranged, and they can ask questions about the product, service, or product functionality.

YouTube determines the efficiency level of a video using its own Analytics option. Thus, the reports on YouTube identify: the number of views, the time tracked quantified in minutes, the identification of the audience (audience demographics) the type of device from which the video was watched, etc. The quality of the YouTube channel is also analyzed translated into performance and interaction with customers.

\section{USING TWITTER TO PROMOTE YOUR BUSINESS}

Launched in 2006, Twitter is a social network that allows you to send to your target audience quick messages limited to 140 characters, various updates on the activities undertaken allowing you to receive quick feedback. Promotion on Twitter is done through promoted tweets, promoted business 
promoted accounts or promoted trends. At first Twitter was considered a minimalist platform, the posting of texts was a maximum of 140 characters, but at the moment you can also post images, videos, emphasizing communication. Up to 280 characters can currently be posted on Twitter.

Twitter uses user actions (subscription, posting, search, interaction) to present those ads that are considered relevant to the user. Ads can be similar to topics searched on Twitter or depending on the user's location. Twitter also provides feedback for viewed ads, and some ads may be disabled in their display if they are deemed unnecessary and irrelevant to use. Promoted accounts increase the chances that the public will purchase the products of the company that promotes its activity on Twitter. The Twitter platform provides visibility, tweets reach users looking for company information very quickly, those messages written on Twitter are quickly indexed and then provided in search results.

Advertising on Twitter can also be done through Twitter Ads to increase the number of visitors to the company's website, the number of users on Twitter, the degree of appreciation of users towards the company. Unlike other platforms, Twitter focuses on real-time communication. To fully exploit the potential of digital marketing, it is important for industrial firms to be able to assess the impact of online activities on performance. Although globally Twitter is very popular, with over 330 million monthly active users, in Romania it is not widely used as one of the least used social media platforms in our country, with about 350,000 users of which 30,000 are users active according to a study by ZeList. Like other social media platforms, Twitter has Ads, businesses that use Twitter Ads want to address consumers and reach them as easily as possible. In the US, Twitter is used by a young population (18-24 years old) in a percentage of $44 \%$. The Romanian public uses Twitter in a rather small percentage, at the same time not even being in the top 10 most used sites. In the information age and the new economy, e-commerce is one of the main tools for achieving new business, labor and social relations (García et al., 2019). Currently the preferred type of content is video, short to medium length videos can capture attention more easily than text or picture type. Twitter users' expectations are related to current news, and the consumer is constantly changing, but he still needs news.

Social networks can help companies build, maintain, and maintain business relationships with people around the world (Kawasaki et al., 2015). Thus, taking into account Facebook and Twitter, reactions can be managed more easily and quickly, the analysis of their activity can be included in reputation management. Negative reactions would be easier to manage, in a search all the results will be displayed, and the first page would indicate that only positive results appear. The effects of images are manifested both cognitively and emotionally and are given by the content of the image and its structure. Images can be recognized faster than texts, the most interesting being the eye traps (Balaban, 2009). The company's image can be improved by using this platform, it can maintain a permanent contact with the audience, although in Romania it is not widely used.

\section{ORIGINAL PROMOTION THROUGH TIKTOK}

TikTok is a very interactive social platform and is based on the creation of short, funny, suggestive or informative videos, the content depends on the person who broadcasts the video. The duration of a video lasts about 15 seconds, it is a platform for entertainment, promotion and animation of the target audience. The TikTok audience is mostly young, over $65 \%$ of users are under 30, 90\% of TikTok users access the application daily and are active at least one hour a day on this platform. The story of the brand can be told to the public in a creative, interactive and unique way using TikTok. TikTok is an application in which short videos are shared. It is very similar to Instagram in that it has $100 \%$ video content and the emphasis is on rhythmic storytelling (Koskenniemi, 2020).

On TikTok, marketers can come up with more and more attractive ideas that have an effect on the target audience. The advertising format on TikTok is represented by "sponsored hastag challenges" or homepage takeovers. More and more brands choose to collaborate with influencers, who can 
better convey the brand message. TikTok has a growing number of users, especially among young people, being a platform that involves posting and viewing short videos. TikTok has over 800 million monthly active users, being dominated by generation Z (4-24 years old) represented in a percentage of $60 \%$. The author Aitchison (2006) presents in his book the efficiency of marketing: to create exceptional advertising, an agency needs three things: management, creativity and customers to buy the product.

In 2019, the structure of using the TikTok platform in Romania by age categories was:

Table 5. Number of users of the Tik Tok in Romania

\begin{tabular}{|c|c|}
\hline Age (years) & Number of users \\
\hline $14-17$ & 50540 \\
\hline $18-25$ & 63175 \\
\hline $26-35$ & 30306 \\
\hline $36-45$ & 16252 \\
\hline $46-55$ & 13675 \\
\hline $56-65$ & 2387 \\
\hline Total & $\mathbf{1 7 6 3 3 5}$ \\
\hline
\end{tabular}

Source: author processing after https://www.manafu.ro/2019/03/tiktok-romania/

The use of TikTok is constantly growing, this application has been downloaded over a billion times, placing it in 4th place in the top of non-gaming video applications. People are more interested in video content being more interactive, information is easier to assimilate, and the power of concentration and audience attention decreases in front of a monotonous advertisement, with too much text or photos uploaded. Even if TikTok users are young, it must be taken into account that the audience must be formed and the public will age with its preferences. The interactive nature of online marketing facilitates communication between consumers and marketers, this increasing the quality and value of the relationship between the two parties. The environment provided by the Internet creates a place of rapid communication, which renders the possibility of immediate response. The formulation of an Internet marketing strategy takes into account the definition of marketing objectives and the whole business.

\section{CONCLUSIONS}

Online advertising is aimed at a large and often ignored audience, and digital strategies are considered more effective because they can deliver information with content that attracts the public's attention and causes them to show interest in the topic presented. Social media marketing aims to use innovative concepts, and based on them you can create campaigns to increase the number of customers. The main advantage of using the Internet in the company's global strategy is the personalization of the distributed message because the personalized message has a greater impact on the public. Internet marketing, as opposed to conventional marketing, focuses on several aspects related to the digital side, the attraction of the public, and the transformation of the target audience into a customer. Social media marketing allows companies to promote their business in a more original way, as it gains customer trust faster compared to other forms of paid advertising. Suggestive images have a much stronger impact than a very long text, which contains complicated words, the well-defined image arouses curiosity.

Interaction in social media can be achieved through appreciation, reaction, recommendations, reviews or expressing free opinions. The information distributed on social media follows a certain path in posting messages or advertising material, obtaining reactions and appreciations and finally 
distribution by the audience it has reached. Social media advertising is more effective in creating and developing brand awareness because the public receives a dynamic and interactive type of advertising. Digital marketing has transformed the way companies manage and communicate with society and their customers around the world (Diez et al., 2019). Under these conditions, the Internet becomes a necessary tool to face the existing challenges in the field of marketing. Unlike traditional social media promotion tools, the potential for dissemination is much higher, the transmission of messages involves low costs, and the personalization of messages determines a higher level of persuasion of the target audience. Posts on social networks aim to inform the public, increase sales for a particular product and gain consumer sympathy.

\section{REFERENCES}

Aitchison, J. \& Mandache, P. (2006). Inovație în advertising - cum să creezi cele mai bune printad-uri pentru brandurile secolului XXI. Bucharest: Editura Brandbuilders

Argyrisa, Y. A., Wang, Z., Kim, Y. \& Yin, Z. (2020). The effects of visual congruence on increasing consumers' brand engagement: An empirical investigation of influencer marketing on instagram using deep-learning algorithms for automatic image classification. Computers in Human Behavior, 112, 1-46.

Balaban, C. D. (2009). Publicitatea de la planificarea strategică la implementarea media, Iași: Editura Polirom

Cheng, W. W. H., Lam, E. T. H. \& Chiu, D. K. W. (2020). Social media as a platform in academic library marketing: A comparative study. The Journal of Academic Librarianship, 46 (5), 102188, 1-8.

Damian, R. \& Jones, C. (2008). Marketing strategies for engaging the digital generation. British Library Cataloguing-in-Publication Data

Diez-Martin, M., Blanco-Gonzalez, A. \& Prado-Roman, C. (2019). Research Challenges in Digital Marketing: Sustainability. Sustainability, 11(10), 2839, 1-13.

Dwivedi, Y. K., Rana, N. P., Slade, E. L. N. \& Izgin, H. (2019). Editorial Introduction: Advances in Theory and Practice of Digital Marketing. Elsevier, Journal of Retailing and Consumer Services, 53, 101909, 1-11.

García, J. J. L., Lizcano, D., MQ Ramos, C. \& Matos, N. (2019). Digital Marketing Actions That Achieve a Better Attraction and Loyalty of Users: An Analytical Study. Future Internet, 11(6), 130, 1-16.

Godin, S. (2019). Asta înseamnă marketing, Bucharest: Editura Publica.

Herhausen, D., Miočević, D., Morgan, R. E. \& Kleijnen, M. H. P. (2020). The digital marketing capabilities gap. Elsevier. Industrial Marketing Management, 90, 276-290.

Instagram users in Romania. (n.d.). In Napoleon.cat. Retrieved October 2, 2021, from https://napoleoncat.com/stats/instagram-users-in-romania/2019/07/

Kawasaki, G. \& Fitzpatrick, P. (2015). Arta rețelelor sociale. Sfaturi pentru utilizatori experimentați, Bucharest: Editura Publica

Kemp, A., McDougal, E. R. \& Syrdal, H. (2018). The Matchmaking Activity: An Experiential Learning Exercise on Influencer Marketing for the Digital Marketing Classroom, Journal of Marketing Education, 41(2), 141-153.

Kingsnorth, S. (2019). Praise for Digital Marketing Strategy-An integrated approach to online marketing. New York: Kogan Page Publishers

Koskenniemi, I. (2020). How to implement effective social selling on LinkedIn?, Metropolia, Expertise and insight for the future, 1-31.

Overview Social Media in .ro - iulie 2019. (n.d.). In ZeList. Retrieved October 10, 2021, from https://www.zelist.ro/blog/overview-social-media-in-ro-iulie-2019/

Scott, D. M. (2010). Noile reguli de marketing și PR. Bucharest: Editura Publica 
Social Media Marketing-FACEBOOK \& INSTAGRAM MARKETING, LINKEDIN, YOUTUBE \& TIKTOK. (n.d.). In Marketiu. Retrieved October 17, 2021, from https://marketiu.com/socialmedia-marketing

TikTok. (n.d.). In Manafu. Retrieved September 7, 2021, from https://www.manafu.ro/2019/ 03/tiktok-romania/

TikTok Statistics. (n.d.). In Wallaroo. Retrieved September 29, 2021 from https://wallaroomedia. com/ blog/social-media/tiktok-statistics/

Tkaczyk, J. (2016). Digital consumer: Trends and challenges. Impact of digital world on marketing and management, (1), 353-367.

85 Twitter Statistics You Must Know: 2020/2021 Market Share Analysis \& Data. (n.d.). In FinancesOnline. Retrieved October 11, 2021, from https://financesonline.com/twitter-statistics/

5 Twitter Trends for 2021/2022: Latest Predictions According To Experts. (n.d.). In FinancesOnline. Retrieved October 11, 2021, from https://financesonline.com/twitter-trends/

Varma, M., Dhakane, N. \& Pawar, A. (2020). Evaluation of Impact of Instagram on Customer Preferences: The Significance of Online Marketing. International Journal of Scientific \& Technology Research, 9(2), 548-554. 